\title{
Studies on Infrasound Noise Emitted by Wind Turbines of Large Power
}

\author{
T. BOCZAR*, T. MALEC AND D. WOTZKA \\ Faculty of Electrical Engineering, Automatic Control and Computer Science, Opole University of Technology \\ S. Mikołajczyka 5, 45-271 Opole, Poland
}

\begin{abstract}
The subject area of this article applies to study of infrasound signals generated by the work of modern wind turbines. Infrasound noise measurements were conducted in accordance with assumptions of the EN 61400-11 standard. The object of study was a newly commissioned wind farm with a total electrical power equal to $30 \mathrm{MW}$. The considered power station consisted of 15 new wind turbines, each with a capacity of 2 MW. Scope of the analysis performed included designation of time runs, depicting temporal changes, and designation of frequency spectra of the recorded infrasound signals. Evaluation of the impact of changes in wind speed was made. Moreover, the scope of analysis, performed in this field, concerned assessment of the impact on the obtained results values of meteorological parameters related to the applied measurement system. Values obtained from measurements were related to and compared with the limits specified in standards and regulations existing in this field.
\end{abstract}

PACS: 43.28.Dm, 07.10.-h, 46.40.-f, 43.50.-x, 43.50.+y

\section{Introduction}

The problem of infrasound noise generated by modern wind turbines, methods of its measurement, and its nuisance evaluation are issues that require detailed research and determination of reference test methodologies. The level of knowledge on each of these stages is differentiated [1-6]. Furthermore, there is no general perspective, which covers all aspects on the issues. There are theoretical studies that describe generation of acoustic waves by turbine blades and gondola and their propagation in free space $[7,8]$. There are also research methods on noise in the audible range, which allow extension of measurements in the infrasound range [9, 10], whereas the infrasound noise nuisance evaluation shall be conducted only at workplaces.

This study attempted to determine the infrasound noise level generated by operation of modern wind turbines, based on the assumptions of the PN-EN 61400-11 standard. This standard allows for a repeatable determination of the sound power level of a wind turbine for different wind speeds (in practice from 5 to $10 \mathrm{~m} / \mathrm{s}$ ). Measurements according to the standard allow for the sound power level determination in the audible frequency range (from $50 \mathrm{~Hz}$ to $10000 \mathrm{~Hz}$ ) with respect to tonality and directionality (optional). The standard precisely defines requirements for the measuring equipment, measurement procedures, methods of results analysis, uncertainty estimation of the results and recorded data. The standard

* corresponding author; e-mail: t.boczar@po.opole.pl also permits extension of the research on the infrasound (Ref. [10], Annex A.2) but it does not define exactly how to measure it. The present study focuses only on the measurement of the sound pressure level, without its recalculation to the sound power level. This approach allows specifying the range of potential effects of infrasound at the measuring point location. Simultaneously to the measurement of sound levels the wind speed and direction were recorded with accordance to the standard. The achieved results were correlated and subjected to separate analysis. The scope of the performed analysis included determination of runs illustrating changes in the time domain and estimation of frequency spectra of registered infrasound signals. Also the impact of wind speed on the recorded values was evaluated. In conclusion, values derived from measurements were related to and compared with the limits specified in standards and regulations for workplaces.

\section{Characteristics of the turbine under study and the test apparatus}

The object of study was a wind turbine with an electrical capacity of $2 \mathrm{MW}$, which was part of the newly delivered for use wind farm consisted of 15 identical turbines, with a total electrical power of $30 \mathrm{MW}$. Diameter of the turbine blades was $82 \mathrm{~m}$ and the tower height was $90 \mathrm{~m}$. For the tests an extremely standing turbine was selected in order to minimize the impact of low frequency noise emitted by the other turbines.

The measurements were taken using a microphone from B \& K, type 4190 (which is shown in Fig. 1), con- 
nected to the B \& $\mathrm{K}$ instrument, type LAN-XI 3050-A-060. The specified sensing frequencies were in the range from $1.2 \mathrm{~Hz}$ to $20 \mathrm{kHz}$, for which the response is linear within $\pm 3 \mathrm{~dB}$ (see Fig. 2). Meteorological conditions were measured using the weather station from DAVIS Instrument - Vantage Pro2.

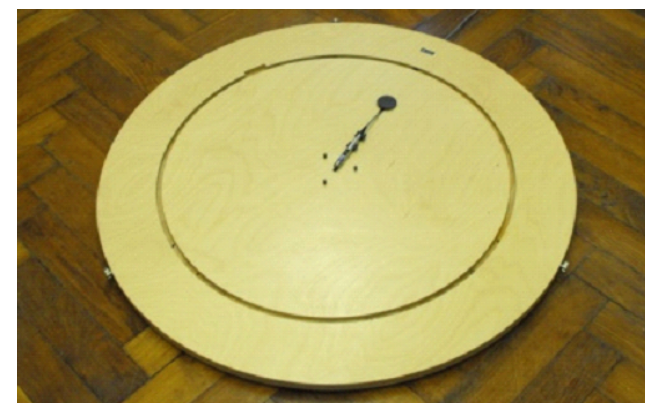

Fig. 1. The measurement setup including B\&K microphone type 4190 at a reflecting plate.

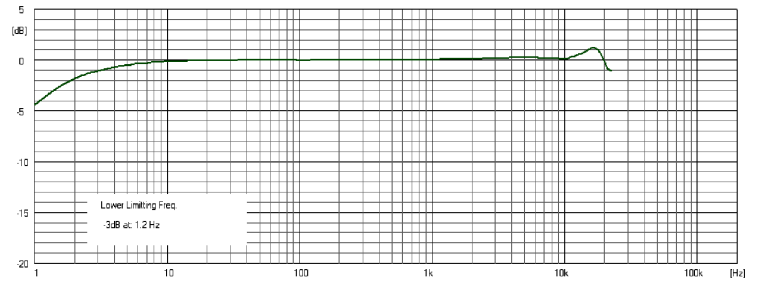

Fig. 2. Free field response $0^{\circ}$ microphone type 4190 with grid protection.

The B \& K LAN-XI instrument enables for research in a wide range of frequencies and for different configurations of the measuring setup. In addition it is equipped with specialized software, PULSE LabShop, which allows for pre-processing of the recorded data. For analysis of the measured signals the MATLAB environment was applied.

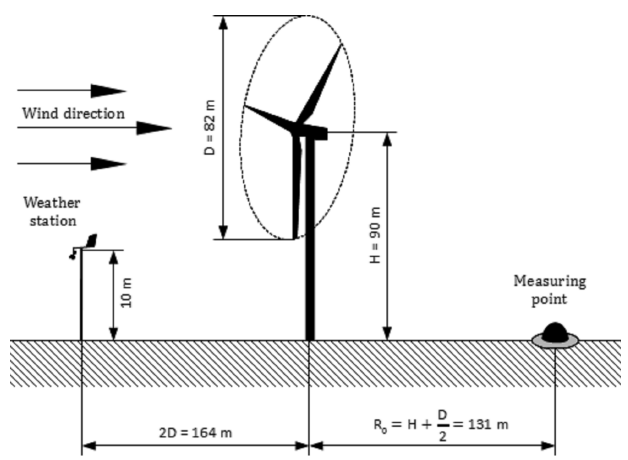

Fig. 3. Schematic diagram of the measuring system deployment of elements relative to test wind turbine.

Measurements of the low frequency noise generated by the test turbine were performed according to the stan-

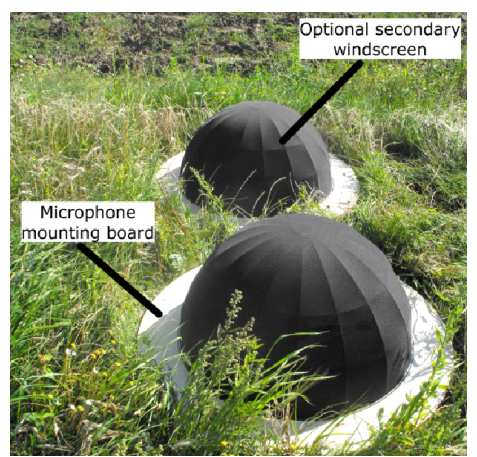

Fig. 4. Microphones setup.

dard at a single reference point $[9,10]$. Location of individual components of the measurement system relative to the test turbine is shown in Fig. 3 and on photograph in Fig. 4. Simultaneously with the measurements of noise levels, wind speed and direction were recorded for later correlation analysis. During measurements the wind speed underwent large fluctuations in the range from 1 to $8 \mathrm{~m} / \mathrm{s}$, which enabled for analysis of its impact on the infrasound level, generated by the test turbine, in a relatively wide range. Other meteorological parameters remained stable and did not undergo significant changes during the measurements. The values are shown in Table.

Summary of meteorological parameters

TABLE occurring during the measurements.

\begin{tabular}{c|c|c|c|c}
\hline \hline $\begin{array}{c}\text { Measured } \\
\text { parameter }\end{array}$ & $\begin{array}{c}\text { Maximal } \\
\text { value }\end{array}$ & $\begin{array}{c}\text { Minimal } \\
\text { value }\end{array}$ & $\begin{array}{c}\text { Average } \\
\text { value }\end{array}$ & $\begin{array}{c}\text { Standard } \\
\text { deviation }\end{array}$ \\
\hline temperature & $24 .{ }^{\circ} \mathrm{C}$ & $17 .{ }^{\circ} \mathrm{C}$ & $21.2{ }^{\circ} \mathrm{C}$ & $2.3{ }^{\circ} \mathrm{C}$ \\
humidity & $71 \%$ & $44 \%$ & $56.5 \%$ & $7.5 \%$ \\
dew point & $13.2{ }^{\circ} \mathrm{C}$ & $11.2{ }^{\circ} \mathrm{C}$ & $12.0{ }^{\circ} \mathrm{C}$ & $0.4{ }^{\circ} \mathrm{C}$ \\
pressure & $1001.6 \mathrm{hPa}$ & $1000.2 \mathrm{hPa}$ & $1000.8 \mathrm{hPa}$ & $0.4 \mathrm{hPa}$ \\
wind speed & $7.6 \mathrm{~m} / \mathrm{s}$ & $1.3 \mathrm{~m} / \mathrm{s}$ & $4.8 \mathrm{~m} / \mathrm{s}$ & $1.4 \mathrm{~m} / \mathrm{s}$ \\
rainfall & $0 \mathrm{~mm}$ & $0 \mathrm{~mm}$ & $0 \mathrm{~mm}$ & $0 \mathrm{~mm}$
\end{tabular}

\section{Analysis of the measurement results}

For comparison issues courses of estimated frequency spectra of the recorded low-frequency acoustic signals measured at different wind velocities are presented in Fig. 5 .

During the measurements the wind speed underwent many changes from 1 to $8 \mathrm{~m} / \mathrm{s}$, while the wind direction was constant during registration. In the study the average sound levels for each of the measured wind speed were calculated. The highest noise levels can be observed for the largest wind speed. Along with decreasing wind speed the sound level generated by the test wind turbine was reduced, where the highest values were observed in the infrasound band (from 3 to $30 \mathrm{~Hz}$ ). In contrast, within the frequency increase the noise level decreased in a linear fashion. In the registered spectra one can distinguish several harmonic components, which significantly stand out from the neighboring components. The first, of the highest level, is in the band from 10 to $30 \mathrm{~Hz}$. 


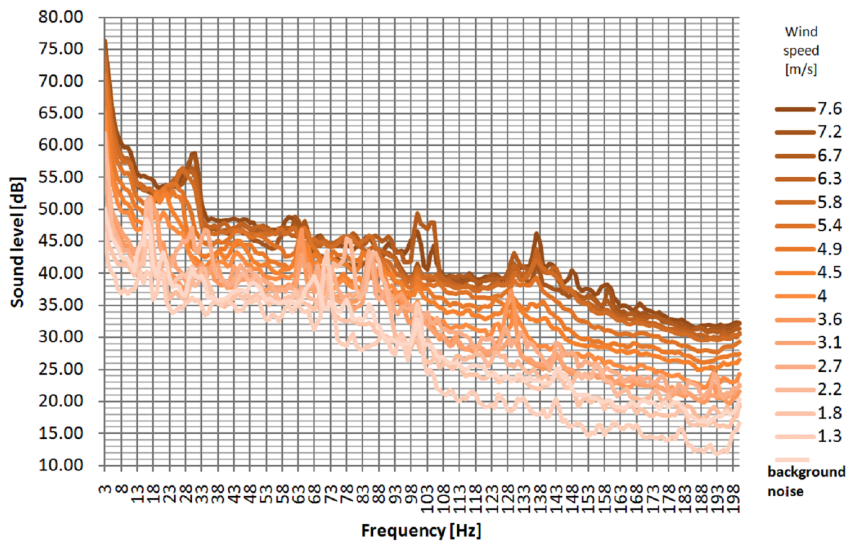

Fig. 5. Amplitude spectra of low-frequency acoustic signals generated by the wind turbine tested determined for different wind velocities.

Its location is correlated with the wind speed. For low wind velocities the maximum of sound pressure level is near $10 \mathrm{~Hz}$. Within the increase of wind speed this maximum is shifting towards higher frequencies and reaches the highest frequency (about $30 \mathrm{~Hz}$ ) for wind speed equal to $7.6 \mathrm{~m} / \mathrm{s}$.

In Fig. 6 a two-dimensional spectrogram, which was calculated for the recorded data using the short time fourier transform (STFT), is presented. It illustrates the temporal changes of the frequency spectrum of the measured sound pressure level, with a sampling rate of $1 \mathrm{~s}$. The dependences presented have been determined without the use of weighting curves (with a flat curve weighting). The highest sound pressure levels can be observed in the range from 3 to $33 \mathrm{~Hz}$, which are the infrasound range components. The highest energy depicts frequency components ranging from 3 to about $10 \mathrm{~Hz}$. The observed sound pressure level does not exceed $90 \mathrm{~dB}$, and in the infrasound band it equals on average $(55-70) \mathrm{dB}$.

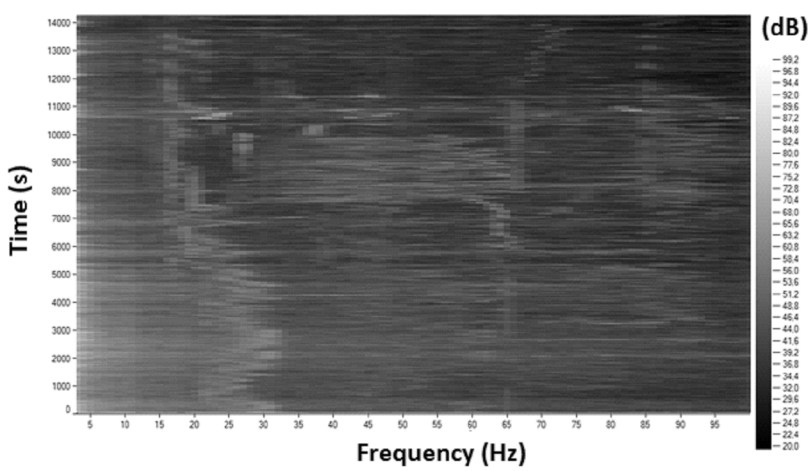

Fig. 6. Two-dimensional spectrogram of sound level in dependence of time and frequency.

Additionally, for a detailed analysis of the low-frequency noise spectra, emitted into the environment by high-power wind turbines, for the particular wind speed values two-dimensional spectrograms, representing changes in sound pressure level for a constant wind speed, were estimated. The results of two selected examples are shown in Figs. 7 and 8. In these spectrograms one can recognize more clearly the range and levels of the components generated by the turbine in the analysed spectrum of the infrasound noise.

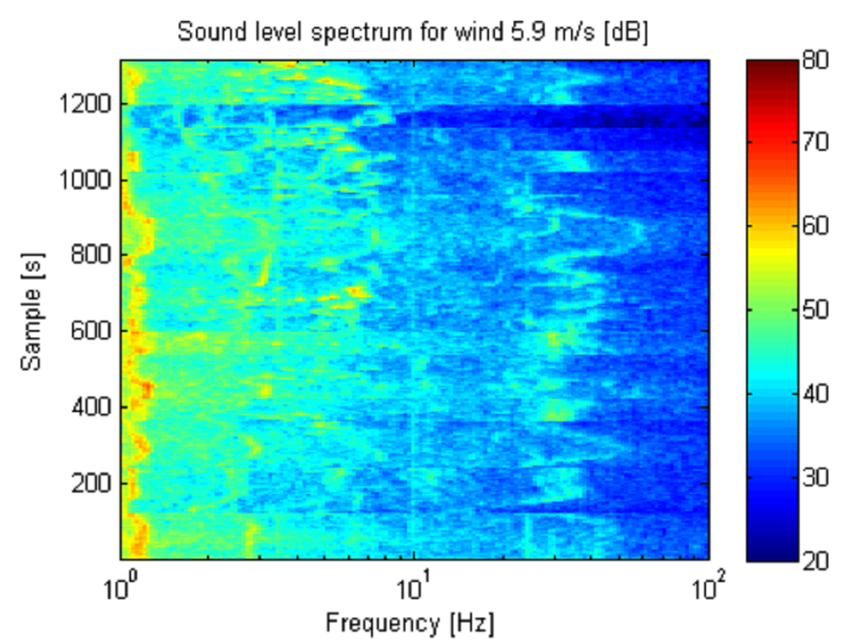

Fig. 7. Two-dimensional spectrogram of sound level in dependence of frequency and subsequent one-second samples for wind speed equal to $5.9 \mathrm{~m} / \mathrm{s}$.

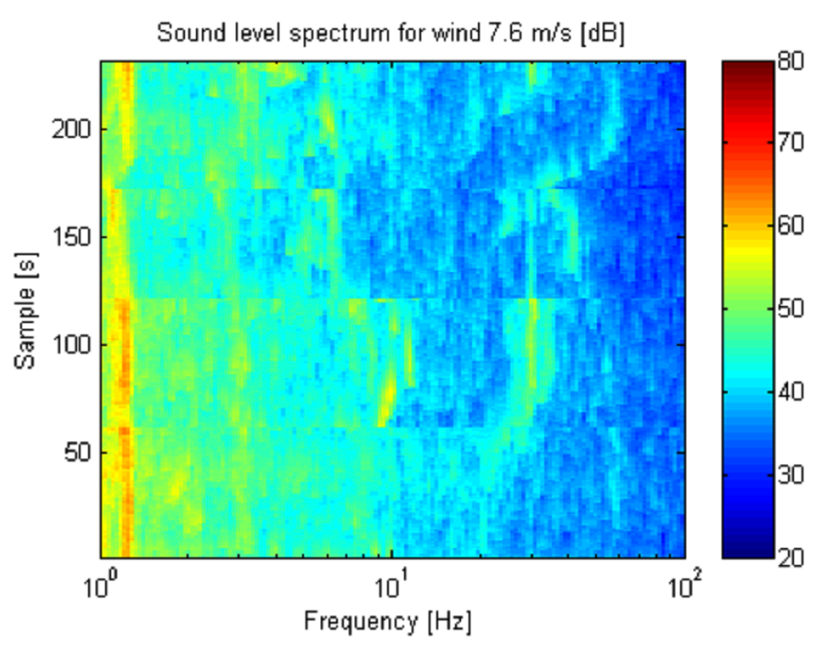

Fig. 8. As in Fig. 7, but for wind speed equal to $7.6 \mathrm{~m} / \mathrm{s}$.

\section{Infrasound noise impact assessment}

The infrasonic noise in the open and publicly accessible environment, including the noise generated by wind turbine operation, is not standardized and has no indicators defined for evaluation of its hazard to humans. However, in the working environment its impact and nuisance were quite thoroughly investigated [11-16] and standards 
for its assessment were developed as well as the limit values have been determined. The infrasonic noise at workplaces is characterized by an equivalent sound pressure level corrected with the $G$ frequency characteristic [12-14]. Its maximum level relative to a working day is equal to $102 \mathrm{dBG}$ (this level is reduced for young persons and pregnant women). In addition to the single number indicator there are also permitted noise levels defined for the octave bands from $10 \mathrm{~Hz}$ to $25 \mathrm{~Hz}$.

Based on the results it can be stated that the operation of wind turbines generates noise containing infrasound components. However, in the case of tested turbine, these levels are well below threshold levels, above which they would be harmful to humans, despite the absence of weighting of the results with the $G$ weighing curve. The results presented constitute a first step of studies related to assessment of the impact of low-frequency noise generated by operation of wind turbines on the environment, including humans. The next stage of research will be associated to the registration and analysis of the pressure level of acoustic signals emitted by wind generators of various power, construction and different operation duration.

\section{References}

[1] G. Bellhose, Low Frequency Noise and Infrasound from Wind Turbines Generators, Willy and Sons, Wellington, New Zealand 2004.

[2] J. Jakobsen, J. Low Freq. Noise, Vibrat. Active Control 24, 76 (2005).
[3] T. Pustelny, A. Opilski, B. Pustelny, Acta Phys. Pol. A 114, A-183 (2008).

[4] C.Y.H. Qibai, H. Shi, J. Low Freq. Noise, Vibrat. Active Control 23, 277 (2004).

[5] D.C. Fernandez Valencia, Infrasound and Its Effects on Humans, Spatial Audio DESC, London 2007.

[6] T. Boczar, Wind Energy utilisation Wydawnictwo PAK, Gliwice 2007 (in Polish).

[7] T. Pustelny, J. Ignac-Nowicka, B. Jarzabek, A. Burian, Opt. Appl. 34, 551 (2004).

[8] S. Wegner, R. Bareiss, G. Guidati, Wind Turbine Noise, Springer, Berlin 1996.

[9] PN-EN 61400-11:2002 Wind turbine generator systems - Part 11: Acoustic noise measurement techniques.

[10] EN 61400-11:2004/A1 Wind turbine generator systems - Part 11: Acoustic noise measurement techniques.

[11] A.J. Swerdlow, Health Effects of Exposure to Ultrasound and Infrasound, Health Protection Agency, Warsaw 2003.

[12] http://www.ciop.pl/6541.html; January 2011 (in Polish).

[13] PN-Z-01338:2010 Acoustics - Measurement and assessment of infrasound noise at work (in Polish).

[14] Regulation of the Minister of Labour and Social Policy, 29.11.2002, Dz. U. 2002 nr 217 poz. 183 (in Polish).

[15] Regulation of the Minister of Labour and Social Policy, 16.06.2009, Dz. U. 2009 nr 105 poz. 1 (in Polish).

[16] T. Malec, Elektryka 342, 51 (2011) (in Polish). 